\title{
PENATAAN KAWASAN TUNJUNGSEKAR SEBAGAI GERBANG KOTA MALANG (RE-DESAIN KAMPUNG KONSERVASI SUNGAI)
}

\author{
Gaguk Sukowiyono \\ Dosen Prodi Arsitektur, Fak. Teknik Sipil dan Perencanaan, ITN Malang \\ e-mail: gaguksukowiyono@yahoo.com \\ Debby Budi Susanti \\ Dosen Prodi Arsitektur, Fak. Teknik Sipil dan Perencanaan, ITN Malang \\ e-mail: budisusantidebby@gmail.com
}

\begin{abstract}
ABSTRAK
Kampung tematik yang menjadi ikon wisata baru di kota Malang cukup menarik perhatian masyarakat, salah satunya adalah Kampung Konservasi Sungai yang terletak di Desa Tunjungsekar kecamatan Lowokwaru kota Malang. Dengan karakter tematik yang berbeda dapat dijadikan sebagai identitas/petanda wilayah tersebut. Dalam perencanaan wilayah kota jangka panjang Desa Tunjungsekar masuk dalam perencanaan wilayah kota bagian Utara sehingga desa ini perlu dilakukan penataan yang berkarakter agar nantinya dapat dijadikan sebagai gerbang masuk Kota Malang dari sisi yang lain. Dengan melihat potensi seperti itu dan keinginan masyarakat yang di dukung oleh pemerintahan setempat (kelurahan) yang menyediakan lahan/tanah bengkok untuk mewujudkannya, maka diperlukan pendampingan. Dengan ilmu yang dipunyai Tim Pendamping dari ITN Malang berupaya untuk mewujudkan ide dan keinginan masyarakat tersebut dengan konsep-konsep penataan kawasan. Pengumpulan dan pengolahan data tentang lokasi penataan dan sekitarnya dilakukan bersamasama antara masyarakat dengan Tim Pendamping yang selanjutnya data-data tersebut dianalisa secara diskriptif untuk di buatkan konsep-konsep yang mengacu pada kondisi lingkungan setempat yang nantinya dituangkan dalam sketsa desain rancangan. Diskusi mematangkan konsep-konsep tersebut dilakukan secara berkala dan terus menerus secara rutin dengan melibatkan unsur masyarakat dan perangkatnya, akademisi, dan unsur pemerintah setempat (kelurahan)
\end{abstract}

Kata kunci: penataan kawasan, identitas, gerbang kota

\section{ABSTRACT}

Thematic villages that become new tourist icons in Malang attract the attention of the community, one of which is the River Conservation Village located in the village of Tunjungsekar,

PAWON: Jurnal Arsitektur, Nomor 02 Volume 3, Bulan Juli-Desember Tahun 2019, ISSN 2597-7636 
Lowokwaru, Malang. With different thematic characters can be used as an identity / mark of the region. In the long-term urban area planning Tunjungsekar Village is included in the planning of the northern part of the city so that this village needs to be structured in a character so that later it can be used as the entrance gate of Malang City from the other side. By looking at such potential and the desires of the people supported by the local government (kelurahan) that provide crooked land / land to make it happen, assistance is needed. With the knowledge that the Companion Team of ITN Malang has, it seeks to realize the ideas and desires of the community with the concepts of regional arrangement. The collection and processing of data about the location of the arrangement and its surroundings is carried out jointly between the community and the Assistance Team, then the data are analyzed descriptively to be made concepts that refer to the local environmental conditions which will be outlined in the design design sketch. The discussion finalized the concepts carried out regularly and continuously on a regular basis involving the elements of society and its equipment, academics, and elements of the local government (kelurahan)

Keywords: area arrangement, identity, city gate

\section{PENDAHULUAN}

\section{Latar Belakang}

Kawasan Tunjungsekar merupakan kawasan yang masuk dalam rencana pengembangan Kota Malang ke depan bagian sisi Utara. Evaluasi terhadap tata ruang wilayah bagian Utara oleh pemerintah Kota Malang yang perkembangannya begitu cepat, sehingga dianggap perlu untuk dilakukan penyesuaian terhadap masterplan yang ada. Rencana pengembangan Jl. Ikan Tombro yang berada di wilayah RW.04 kelurahan Tunjungsekar kecamatan Lowokwaru kota Malang sebagai pemecah kemacetan Jl. Ahmad Yani, menjadikan wilayah ini sebagai alternatif sirkulasi utama keluar masuk kota Malang, sehingga dapat dikatakan bahwa wilayah ini sebagai gerbang ke-2 nya ke kota Malang dari sisi Utara.

Keberagaman penduduk dan pekerjaannya menggambarkan perkembangan sektor ekonomi penduduknya cukup baik, banyak potensipotensi wilayah RW.04 yang dipunyai seperti: bank sampah, kerajinan rumahan dari bahan bekas, dilewatinya wilayah ini oleh sungai yang dimanfaatkan penduduk sekitar sebagai sarana pengairan pertanian dan perkebunan yang masih cukup luas dan dapat menopang perekonomian wilayah, sehingga perlu dijaga dan dikembangkan keberadaan sungai tersebut. 
Posisi wilayah RW.04 kelurahan Tunjungsekar yang terletak pada sisi paling utara kota Malang berbatasan dengan kabupaten Malang merupakan kawasan yang di dominan persawahan apabila dibandingkan dengan bangunan sehingga lingkungan masih alamiah dan jauh dari pencemeran membuat kawasan ini menarik sebagai kawasan untuk menetap tinggal. Banyaknya minat investor membangun perumahan diwilayah ini yang semakin lama semakin banyak dan berkurannya kawasan persawahan.

Pemanfaatan pemandangan alam yang indah sebagai view keluar dan kedalam serta pengolahan kawasan, menjadi salah satu alasan masyarakat sekitar yang bekerjasama dengan ITN Malang sebagai pendamping dalam melakukan konservasi sungai. Lingkungan yang asri dan alami membuat kualitas lingkungan menjadi baik. Kejernihan aliran sungai yang ada dengan debit yang cukup baik sehingga kondisi sungai dapat meningkatkan kehidupan masyarakat kampung yang berada disepanjang tepian sungai.

\section{TUJUAN dan SASARAN}

Tujuan yang ingin dicapai dari konsep penataan kawasan Tunjungsekar sebagai gerban kota Malang ini adalah sebagai berikut :

- Menghadirkan kawasan yang berkarakter

- Dapat dijadikan sebagai gerbang masuk kota Malang

- Konservasi dan pelestarian sungai sebagai penopang kehidupan masyarakat kampung yang ada di sepanjang tepian sungai.

- Wisata edukasi lingkungan dan teknologi sederhana

- Peningkatan perekonomian masyarakat sekitar

- Menciptakan lapangan kerja baru dan mengurangi angka pengangguran di Kelurahan Tunjungsekar

Sasaran dari konsep dan gagasan adalah sebagai berikut :

- Sepanjang aliran sungai dimulai dari RW.06 kelurahan Tasikmadu sampai dengan RW.04 kelurahan Tunjungsekar

- Masyarakat RW.04 khususnya dan kelurahan Tunjungsekar umumnya

- Masyarakat Kota Malang secara keseluruhan

- Adanya alih teknologi dan IPTEK dari akademisi kepada masyarakat

\section{METODE PENELITIAN}

\section{Metode Pengumpulan Data}

Data dibedakan menjadi 2 (dua), yaitu : data primer dan data sekunder. Data primer adalah data yang diperoleh langsung di lapangan, sedangkan data sekunder adalah data yang melengkapi data primer, yaitu yang diperoleh dari instansi terkait berupa buku/dokumen/catatan yang diteliti atau suatu hasil penelitian. 
Untuk mendapatkan data yang tepat dan dapat mendukung proses analisis, maka ada beberapa hal yang perlu diperhatikan dalam pengambilan data, yaitu: menentukan faktor pengaruh, menentukan jenis data apa yang dibutuhkan, menentukan sumber-sumber data yang relevan, menentukan cara mendapatkan data dan alat yang digunakan untuk mendapatkan data tersebut.

Data-data yang diperlukan dalam kegiatan pengabdian kepada masyarakat ini adalah sebagai berikut:

1. Kondisi eksisting, guna mengetahui potensi dan permasalahan yang ada di lingkungan kawasan penataan dan sekitarnya.

2. Fisik dan non fisik, untuk mengetahui gambaran kondisi lingkungan kawasan penataan secara detail, kondisi geografi pada lokasi penataan dan klimatologinya, masyarakat dan huniannya, serta aksesibilitasnya.

3. Wawancara warga sekitar, tokoh masyarakat, dan perangkat kelurahan, untuk mengetahui batas administrasi dan kepemilikan lahan secara jelas, mengetahui kondisi kawasan secara sosial, ekonomi dan budaya masyarakatnya secara umum di wilayah Desa Tunjngsekar, menggali sifat dan perilaku masyarakat sekitar kawasan penataan dalam upaya mempersiapkan diri menghadapi perubahan lingkungannya.

4. Mencari data tanaman konservasi dan tanaman estetika, untuk mengetahui jenis tanaman yang dapat digunakan sebagai sarana mengkonservasi sungai dan berunsur estetika untuk mendukung lingkungan kawasan penataan sehingga berkarakter kuat dan dapat dijadikan sebagai identitas/petanda kawasan.

\section{Alat yang Digunakan}

Dalam mendapatkankan data yang valid dalam kegiatan pengabdian kepada masyarakat peralatan yang digunakan adalah sebagai berikut:

- Roll Meter, untuk mengukur dimensi dan infrastruktur sungai.

- Kamera/video/drone, untuk mendokumentasi-kan keadaan fisik kawasan penataan dan lingkungannya.

- Alat ukur kedalaman dan kedangkalan sungai.

- Data kondisi lingkungan penataan saat musim penghujan dan kemarau

- Papan sketsa dan kertas gambar

- Alat perekam audio

\section{Waktu Pengukuran}

Pengukuran lapangan dan perekaman kondisi lingkungan secara fisik dan non fisik dilakukan pada obyek pengabdian kepada masyarakat dalam waktu \pm 2 (dua) bulan, secara berkala dalam satu hari dilakukan selama \pm 2 jam amatan, dan dalam satu minggunya dilakukan selama 2 (dua) kali. 
Pengukuran dan amatan dilakukan saat aktivitas kawasan penataan berjalan secara rutin dalam kesehariannya.

Diskusi dengan seluruh elemen masyarakat, tokoh masyarakat, dan pejabat berwenang yang dianggap berhubungan langsung dengan kegiatan pengabdian ini dilakukan secara periodik dan terus menerus selama \pm 6 (enam) bulan. Selanjutnya hasilnya akan diolah dan dikaji serta dituangkan dalam usulan rancangan \pm 5 (lima) bulan yang mana selama pembuatan rancangan tetap dilakukan diskusi dengan elemen yang ada.

\section{HASIL DAN PEMBAHASAN}

\section{Target}

Mengolah dan menata tapak yang ada (tanah bengkok kelurahan Tunjungsekar) dalam bentuk desain kawasan dengan memperhatikan karakter yang dipunyai, sehingga dapat dimunculkan identitas/petanda kawasan yang berkarakter yang nantinya dapat dijadikan sebagai gerbang masuk ke-2 (dua) kota Malang dari sisi lain.

\section{Luaran}

Luaran yang dimunculkan adalah membuat konsep dan sketsa desain rancangan dalam upaya penataan kawasan berdasarkan pada potensi yang ada.

\section{Point Perencanaan}

Point perencanaan di tentukan berdasarkan hasil FGD dengan masyarakat serta melalui analisa terhadap potensi dan kendala yang ada guna menciptakan kawasan kampung berbasis konservasi sungai.

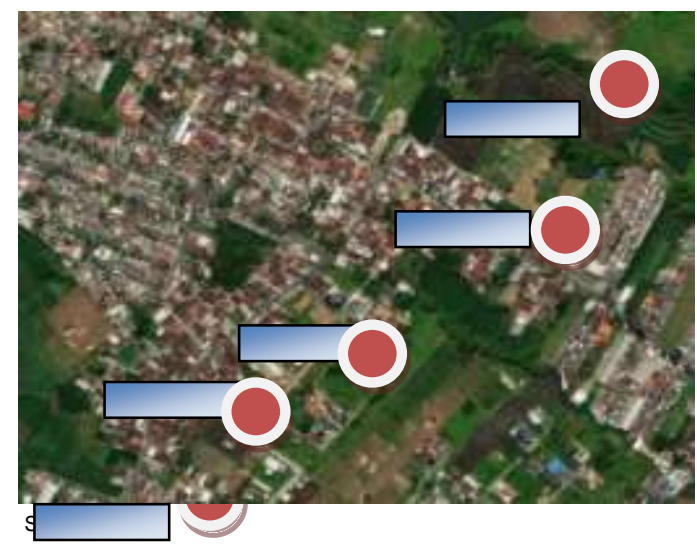

Gambar 1. Point-

Point-Point perencanaan penataan kawasan kelurahan Tunjungsekar sebagai gerbang kota Malang (re-desain kampung konservasi sungai) meliputi 5 (lima) point perancangan yaitu: 
a. Point 1, Perencanaan Gapura Kawasan Kampung Konservasi Sungai Berfungsi sebagai gerbang utama terhadap Kampung Konservasi Sungai, titik ini juga sebagai titik awal dalam perencanaan.

b. Point 2, Penataan Koridor di sepanjang jalan poros Kampung Konservasi Sungai. Tepatnya berada di jalan Ikan Tombro di lingkungan Rw 04 Kelurahan Tunjungsekar.

c. Point 3, Penataan Lokasi Pakir Kendaraan bagi pengunjung Kampung Konservasi Sungai.

d. Point 4, Perencanaan Gapura Taman Bambu Mewek. Gapura ini berfungsi sebagai gerbang masuk ke area Taman Bambu Mewek.

e. Point 5, Perencanaan Taman Bambu Mewek. Taman ini nantinya berfungsi sebagai taman wisata dan edukasi yang berlandaskan konservasi Sungai Mewek.

\section{Analisa dan Konsep}

Analisa dan konsep dari kegiatan perencanaan ini ditinjau dari potensi dan kendala yang terdapat pada masing-masing titik perencanaan, sehingga nantinya dapat diketahui konten yang terkandung didalamnya.

\section{- Analisa dan Konsep pada Titik 1}

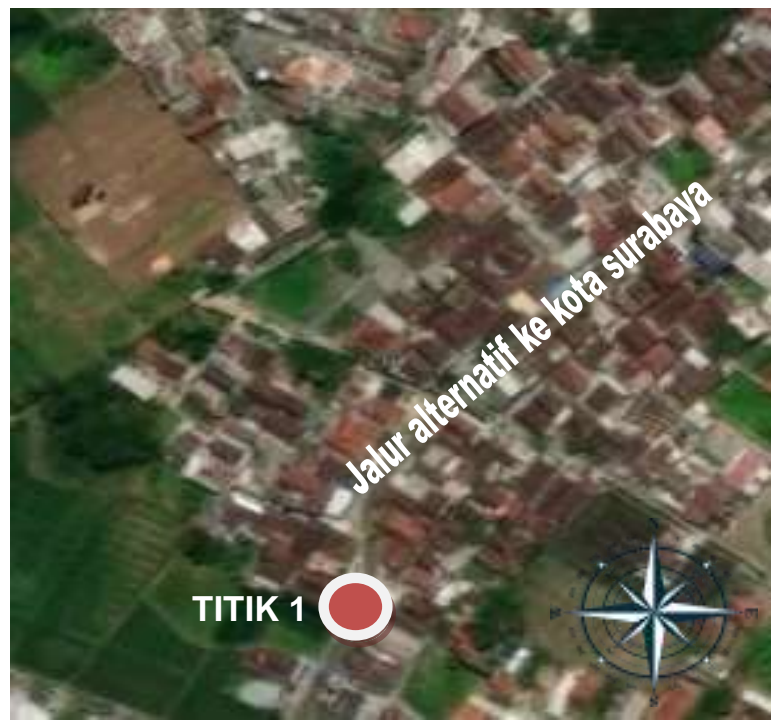

Sumber : Mapbox.com

Gambar 2. Lokasi titik 1 


\section{a. Analisa Potensi dan Kendala}

\section{Potensi:}

1. Titik 1 merupakan akses utama menuju lingkungan RW.04 kelurahan Tunjungsekar kecamatan Lowokwaru dari arah kota Malang, serta merupakan perbatasan antara kelurahan Tunjungsekar dengan kelurahan Mojolangu.

2. Titik 1 juga merupakan jalan masuk dari jalur alternatif menuju ke kota surabaya.

\section{Kendala:}

1. Pada titik 1 sering terjadi kemacetan terutama saat jam pulang kerja

2. Terdapat jembatan dan jalan menanjak, sehingga pengguna jalan perlu berhati-hati.

\section{b. Konsep Perencanaan}

Di Perlukan Gapura yang berfungsi sebagai gerbang masuk ke dalam lingkungan kampung konservasi sungai yang mampu mencitrakan keistimewaan dari kampung tersebut. Point-point yang perlu diangkat antara lain:

1. Elemen alam yang ada di sungai seperti batuan, tanaman dan lainnya.

2. Elemen bambu sebagai identitas dari kawasan kampung konservasi sungai tersebut, yang mana inti dari kawasan kampung konservasi sungai ini ialah taman bambu mewek yang terdapat disisi Timur-Selatan sungai mewek..
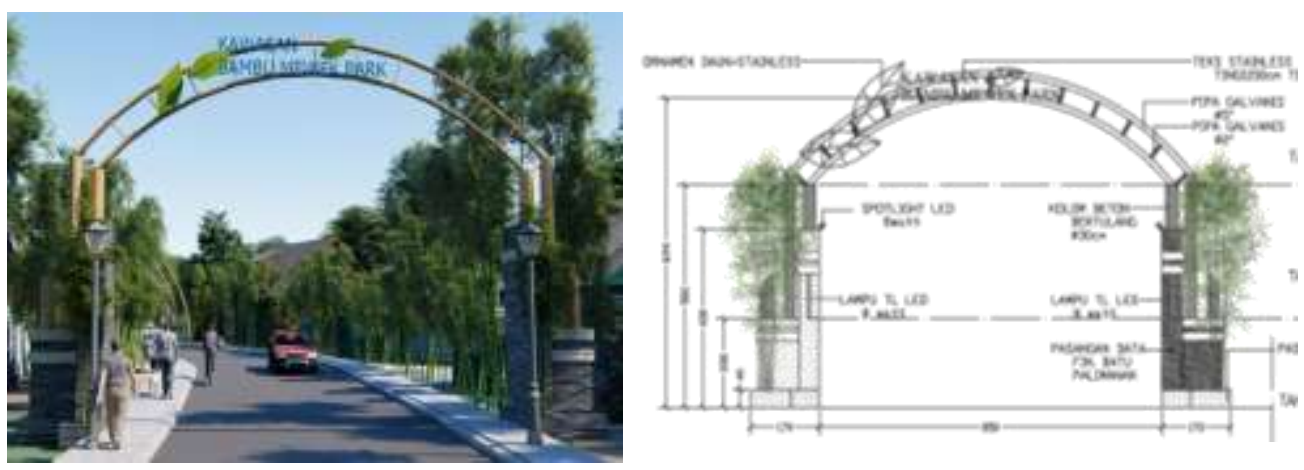

sumber: dokumen penulis

Gambar 3. Desain Gapura Kawasan pada point 1

3. Selain Gapura, pada point 1 (satu) juga di rencanakan sebuah pergola yang berfungsi sebagai peneduh dan memperkuat identitas dari kampung konservasi sungai yang bertemakan bambu. Hal ini akan memudahkan masyarakat mengenali kawasan perencanaan yang dilewati sebagai gerbang ke-2 'dari' dan

PAWON: Jurnal Arsitektur, Nomor 02 Volume 3, Bulan Juli-Desember Tahun 2019, ISSN 2597-7636 
'ke' kota Malang. Adapun perletakan pergola ini pada 3 (tiga) titik yang merupakan batas wilayah RW.04 kelurahan Tunjungsekar.

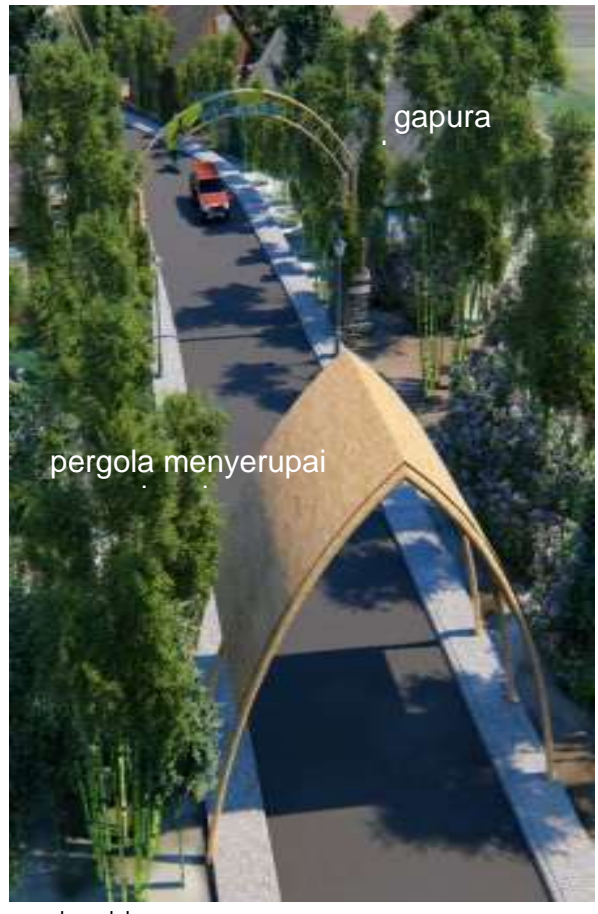

sumber: dokumen

Gambar 4. Konsep Desain

- Analisa dan Konsep pada Titik 2

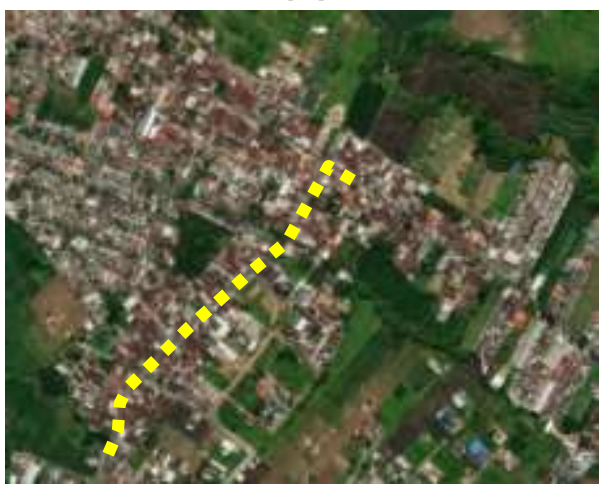

Gambar 5. Jalur penataan koridor pada titik 2 


\section{a. Analisa Potensi dan Kendala}

\section{Potensi:}

1. Point ini merupakan jalur alternatif menuju kota surabaya yang biasanya sering di gunakan oleh masyarakat untuk menghindari arus padat lalu lintas di jalur utama.

2. Kondisi Lingkungan yang bersih, di harapkan tidak ada kendala yang berarti pada saat perawatan nantinya.

3. Kondisi jalan cukup baik, tidak berlubang, serta terdapat drainase di kedua sisi jalannya.

\section{Kendala:}

1. Kondisi jalan saat ini tidak terlalu lebar.

2. Intensitas kendaraan pada jalur ini cukup tinggi, terutama pada saat jam pulang kerja.

3. Saat ini masih banyak kendaraan yang parkir di daerah milik jalan (bahu jalan).

\section{b. Konsep Perencanaan}

Lingkup penataan koridor pada kawasan kampung konservasi sungai ini antara lain:

1. Penanaman bambu hias di tiap sisi jalan yang bertujuan untuk memperindah koridor serta memperkuat identitas/karakter lingkungan dari kampung konservasi sungai yang bertemakan bambu ini.

2. Pemberian gazebo di beberapa titik sepanjang koridor jalan kawasan yang berfungsi sebagai tempat berkumpul warga ataupun tempat istirahat bagi pengunjung.

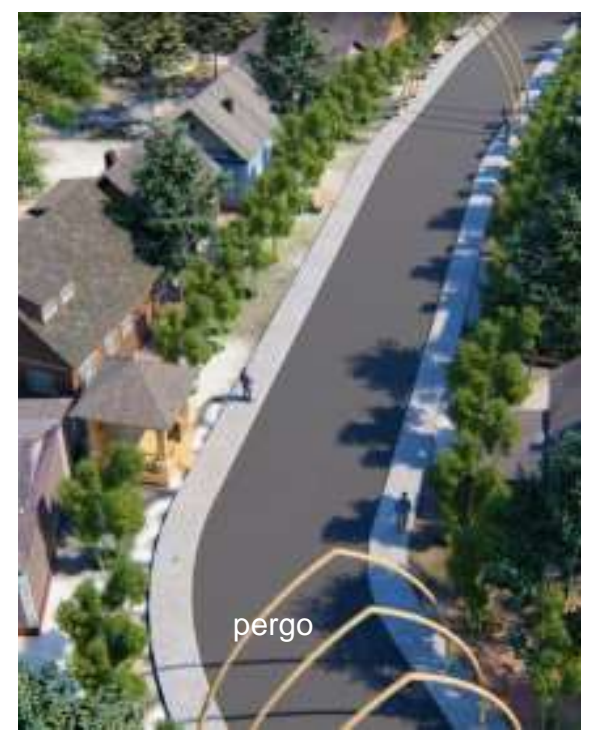

sumber :
Penanaman bambu hias di sepanjang koridor disarankan menggunakan bahan bekas (lahan sempit, di atas selokan, dil), misal: penggunaan ban mobil bekas

PAWON: Jurnal Arsitektur, Nomor 02 Volume 3, Bulan Juli-Desember Tahun 2019, ISSN 2597-7636 


\section{- Analisa dan Konsep pada Titik 3}

Titik 3 (tiga) merupakan lokasi yang akan di jadikan tempat parkir bagi pengunjung kampung konservasi sungai. Hal ini dengan pertimbangan pada lahan yang cukup relevan untuk digunakan.

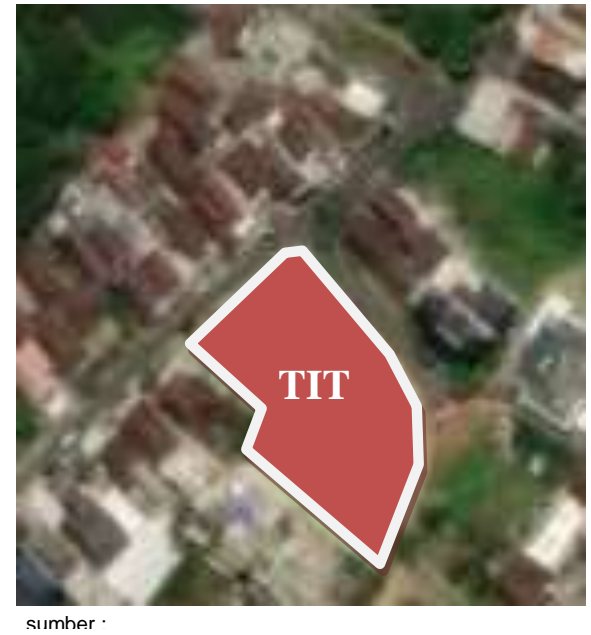

Gambar 7. Peta

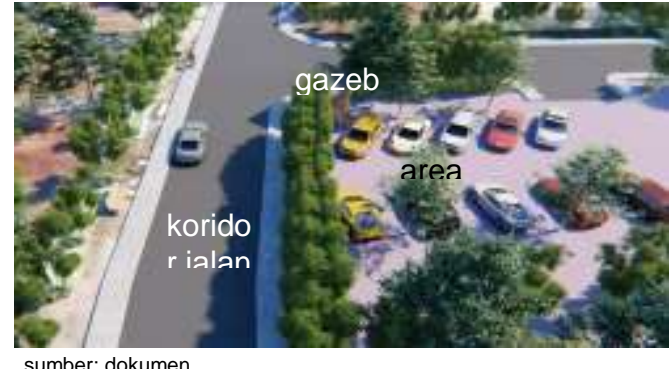

Gambar 8. Visual desain pada

\section{a. Analisa Potensi dan Kendala}

\section{Potensi:}

1. Lahan cukup besar, yaitu $\pm 911 \mathrm{~m}^{2}$

2. Lahan berada di sisi koridor serta dekat dengan kampung konservasi sungai.

\section{Kendala:}

1. Status lahan

2. Lahan berada bersebelahan dengan rumah warga, kemungkinan nantinya tempat ini akan sangat bising akibat kendaraan yang keluar masuk.

\section{b. Konsep Perancangan}

Lingkup perencanaan tempat parkir pada kawasan kampung konservasi sungai ini antara lain:

1. Pavingisasi

2. Pemberian gazebo sebagai tempat berjaga dan istirahat.

\section{KESIMPULAN}

Dari uraian di atas, maka dapat disimpulkan bahwa dalam suatu perencanaan berdasarkan optimalisasi potensi suatu kawasan dimana di 
dalamnya ada keterpaduan antara elemen masyarakat sekitar dan dinas terkait serta unsur lain yang kompeten dalam suatu perencanaan, akan menjadikan suatu karya itu berkarakter lokal yang kuat yang mencirikan wilayah tersebut.

Wujud keterpaduan tersebut diaplikasikan dalam perencanaan penataan kawasan sebagai gerbang kota dari sisi lain yang kuat karakter wilayahnya, sehingga dapat dijadikan sebagai petanda/ identitas/ gerbang masuk suatu wilayah kota.

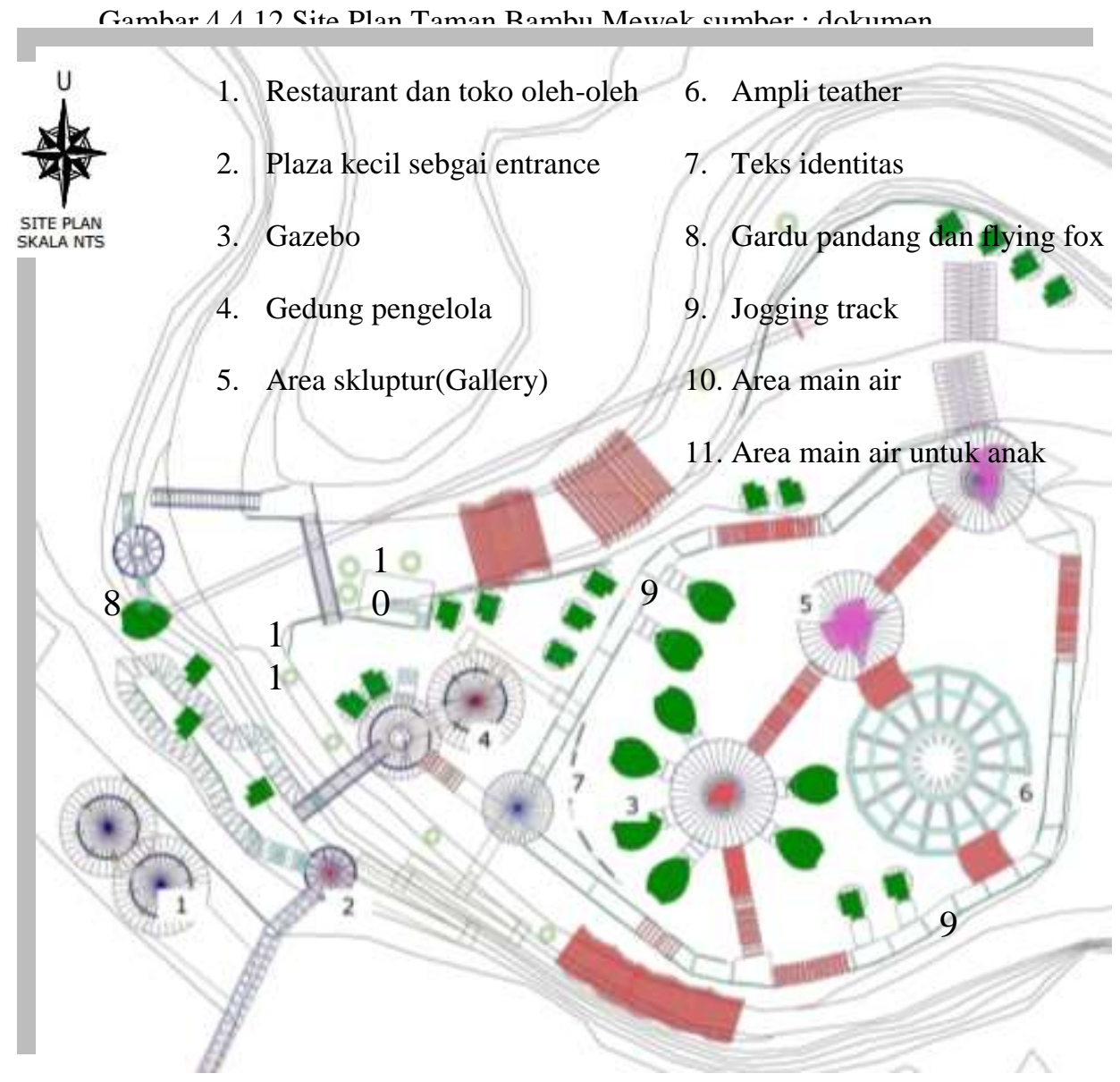




\section{DAFTAR PUSTAKA}

1. Gunadi, Sugeng. 1989. Pdoman Perancangan Tapak dan Lingkungan. Utama Press. Surabaya.

2. Hakim, Rustam. 1993. Unsur Perancangan Dalam Arsitektur Lansekap. Penerbit Bumi Aksara. Bandung.

3. Paimin, dkk. 2012. Sistem Perencanaan Daerah Aliran Sungai. Pusat Penelitian dan Pengembangan Konservasi \& Rehabilitasi (P3KR). Bogor.

4. Suprayogi Slamet, dkk. 2014. Pengelolaan Daerah Aliran Sungai. Gadjah Mada University Press. Yogjakarta.

5. Tim Kompas. 2010. Jelajah Musi, Eksotika Sungai di Ujung Senja. Penerbit Buku Kompas. 